\title{
A Dinâmica dos Fluidos Complementada e a Sustentação da Asa
}

Complementation of fluid dynamics and aerodynamic lift

\author{
Klaus Weltner*, Martin Ingelman-Sundberg**, Antonio Sergio Esperidião* e Paulo Miranda* \\ * Instituto de Física da UFBA, Rua Caetano Moura, 123 - Federação \\ Campus Universitário de Ondina CEP: 40.210-340, Salvador, Bahia \\ ${ }^{* *}$ Smedsbacksgatan 5, 11539 Stockholm, Sweden \\ e-mail:weltner@ufba.br
}

Recebido em 08 de Setembro de 2000. Manuscrito revisado em 05 de Setembro de 2001. Aceito em 15 de Janeiro de 2002.

\begin{abstract}
A explicação convencional da sustentação da asa, usando a lei de Bernoulli, apresenta equívocos graves que são aqui analisados. Usamos as leis de Newton para demonstrar coerentemente a sustentação que se origina na aceleração do ar para baixo pela asa. A velocidade do fluxo de ar acima da asa é maior do que abaixo dela. Mostramos que isto é decorrência e não causa da baixa pressão. Se uma linha de corrente for curva existe um gradiente de pressão perpendicular à velocidade, fato que não pode ser negligenciado na representação da dinâmica dos fluidos. A análise da curvatura das linhas de corrente em volta de um obstáculo esclarece a geração e a distribuição das pressões. Outras aplicações equivocadas da lei de Bernoulli são detalhadamente analisadas segundo o nosso enfoque. Apresentamos experimentos convincentes e facilmente realizáveis em sala de aula, compreensíveis mesmo para o ensino médio.
\end{abstract}

The conventional explanation of aerodynamic lift based on Bernoulli's law has important mistakes, which are pointed out. Lift is be explained here in a coherent way using Newton's laws. We show that the higher streaming velocity at the upper side of an aerofoil is the consequence but not the cause of the lower pressure. The cause of lift is the downward acceleration of air by the aerofoil. For a detailed analysis we regard the normal acceleration of air in case of curved streamlines that results in pressure gradients perpendicular to the streamlines. The analysis of curvature of streamlines in the vicinity of obstacles shows the generation of pressure distribution on the surface. Other misleading and erroneous aplications of Bernoulli's law are also analyzed and corrected. We present classroom experiments to demonstrate convincingly the downward movement of air caused by an aerofoil and the generation of pressure by the deflection of air stream.

\section{Introdução}

A análise do vôo pode despertar interesse para o estudo da Física mas normalmente esta motivação não é usada. Uma causa disto pode ser a maneira pela qual este assunto é tratado. A explicação convencional da sustentação da asa, baseada na lei de Bernoulli, diz que a pressão menor acima da asa é a conseqüência de uma maior velocidade do ar acima dela. Este raciocínio tem defeitos fundamentais pois não dá uma causa para a maior velocidade do ar acima da asa. A abordagem apresentada aqui foi inicialmente proposta por Smith [1], Fletcher [2] e Weltner [3]. Ela se baseia nas leis de Newton e particularmente nas equações da Hidrodinâmica de Euler. A asa do avião tem um ângulo de ataque em relação à direção do próprio movimento. A asa força o ar em torno dela a se mover para baixo, acelerando-o nesta direção. A contra-força (reação do ar), orientada para cima, é a sustentação. Esta abordagem é adotada por alguns livros-textos como o do Halliday - Resnick [4] e o de Bergmann-Schaefer [5]. Além disso nas discussões internacionais contemporâneas aparecem vários trabalhos que mostram erros na aplicação da lei de Bernoulli para a sustentação da asa como Anderson e Eberhardt [6], Craig [7] e Waltham [8]. Sabemos que, se uma explicação errada for profundamente radicada, é bastante difícil substituí-la. Certamente por isso, as explicações convencionais ainda sobrevivem com uma certa inércia na maioria dos livros-textos, até mesmo nos manuais 
dos pilotos. Neste trabalho procuraremos propositadamente ilustrar este novo ponto de vista com experimentos de fácil reprodução e de baixo custo. Nos capítulos seguintes mostramos como uma lacuna na apresentação da dinâmica dos fluidos, presente na maioria dos textos, tenha possivelmente causado aplicações erradas da lei de Bernoulli. Propomos a análise da curvatura do escoamento de um fluido como uma ferramenta forte para entender a geração e distribuição das pressões em torno de um obstáculo. Este trabalho está baseado na referência [3] de um dos autores com adequações e extensões.

\section{Sustentação da asa}

\section{II.1 Análise das explicações conven- cionais}

A explicação convencional, encontrada na maioria dos livros-texto de Física, aplica a lei de Bernoulli ao escoamento do ar em torno de uma asa de forma equivocada. A lei nos diz que: no escoamento de um fluido a pressão é tanto menor quanto maior for a sua velocidade. Pelas análises das fotos de filetes de escoamento do ar em torno da asa em túneis de vento verifica-se que a densidade dos filetes é maior acima da asa do que abaixo dela. Então, considerando a velocidade do ar maior acima da asa do que abaixo dela, e tendo em vista a lei de Bernoulli, deduz-se que esta maior velocidade do ar causa uma pressão menor. Este raciocínio é incompleto. Falta explicar como a asa causa estas diferenças nas velocidades. Esta falta é fundamental. Sem entender como a asa modifica as velocidades do escoamento do ar, não se compreende o seu papel. Destaquemos alguns parágrafos retirados dos livros-texto que tratam deste assunto.

i) Raciocínio levando em consideração os comprimentos dos caminhos percorridos pelo ar. [9]

"A Fig. 1 mostra o aspecto das linhas de corrente do escoamento em torno de um aerofólio, no plano da seção transversal. A velocidade do ar é maior na parte superior da asa do que na inferior (o ar tem uma distância maior a percorrer por cima). Novamente, pela equação de Bernoulli (fenômeno de Venturi), a velocidade maior do escoamento reduz a pressão na parte superior, e o empuxo dinâmico $\mathbf{E}$ resultante sustenta o avião"

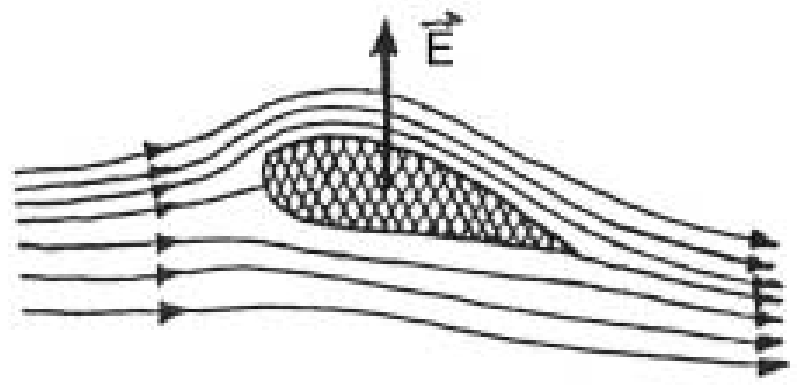

Figura 1. Escoamento do ar em torno da asa [9].

Este raciocínio se baseia na hipótese de que as partículas do ar que estavam juntas à frente da asa se juntem novamente atrás dela. Smith (1972) [1] destacou que esta hipótese não tem nenhuma justificativa na teoria e é errada. Realmente, as Figs. $2 \mathrm{a}$ e $2 \mathrm{~b}$ mostram que as partículas do ar que estavam juntas à frente da asa nunca mais se juntarão atrás dela.

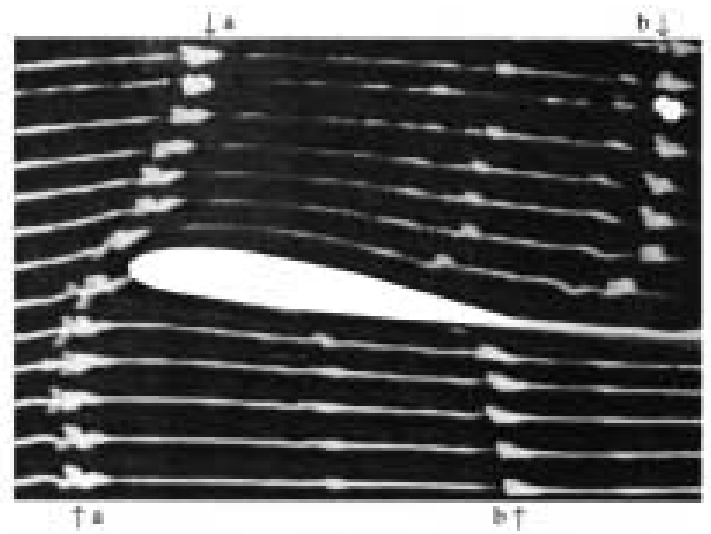

Figura 2a. Linhas de escoamento em torno da asa. Copia de uma foto de um escoamento real com marcadores de fumaça.
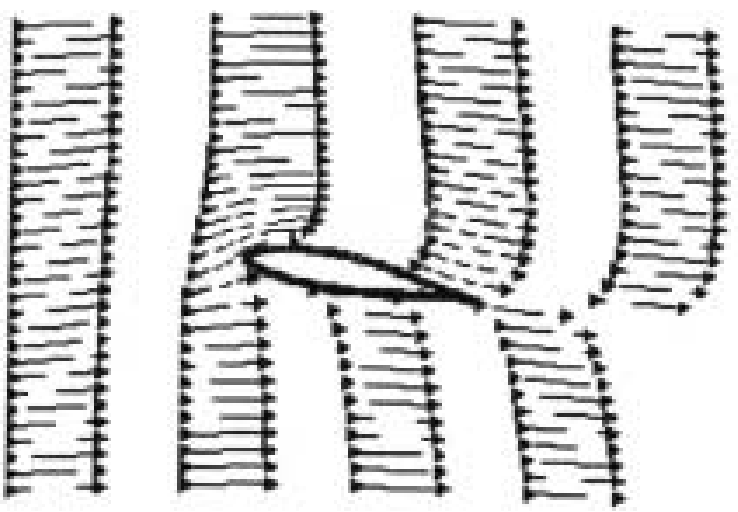

Figura 2b. Escoamento calculado teoricamente [6].

A diferença das distâncias percorridas não pode estar relacionada com as diferenças geométricas existentes acima e abaixo da asa. O raciocínio é totalmente equivocado e deve ser evitado, pois as partículas do ar não 
podem saber, a priori, que a distância a ser percorrida acima da asa é maior do que abaixo dela e por isso devem ter maior velocidade acima do que abaixo para não se separarem no final dos dois percursos [1].

\section{ii) Raciocínio a respeito da circulação}

A circulação é um conceito matemático aplicado ao escoamento dos fluidos. É a integral de linha do produto escalar da velocidade com o elemento de linha. Se esta integração for realizada ao longo de um caminho fechado e não for nula, o seu valor é a circulação. Se as velocidades acima e abaixo da asa têm diferenças, esta integral não pode ser nula, indicando uma circulação. Existem autores que apresentam a circulação como causa da distribuição das velocidades em torno da asa [10]. Se for usada como explicação, temos que esclarecer como a asa a gera. Por enquanto, o conceito de circulação é uma descrição matemática da distribuição das velocidades mas não é uma explicação. Discutiremos este assunto em mais detalhes no apêndice 8.1 para mostrar que o desvio do escoamento para baixo causado pela asa resulta numa circulação.

\section{iii) Raciocínios irrelevantes}

Frases do tipo "A forma da asa leva o ar a escoar assim" só servem para ocultar a falta de uma explicação convincente e coerente.

Conclusão: Podemos dizer que a explicação convencional encontrada na maioria dos livros textos para a sustentação da asa é incompleta ou melhor, errada. Podemos adiantar, pois explicaremos mais adiante, que a origem deste dilema é o fato de que a maior velocidade do ar acima da asa é uma conseqüência de uma menor pressão e não a causa dela.

\section{II.2. Raciocínio básico: A sustentação da asa é a força de reação}

A explicação da sustentação do rotor de um helicóptero é comumente baseada nas leis da mecânica. Um fluxo de ar é empurrado e acelerado para baixo. Para isso o rotor exerce uma força sobre o ar. A reação é a sustentação. Analogamente se explica a propulsão a hélice ou a jato. Neste caso a asa exerce a mesma função da hélice do helicóptero. A asa é uma superfície um pouco curva com um certo ângulo de ataque que é fundamental para o seu comportamento no fluxo de ar. Fig. 3 .

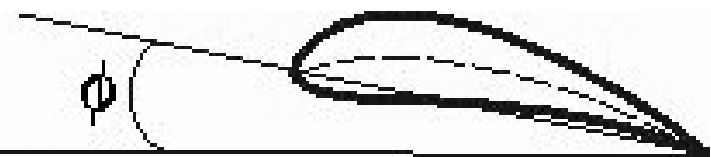

Figura 3. O ângulo de ataque é o ângulo entre a direção do movimento da asa e a secante que passa pelos pontos anterior e posterior mais distantes da linha média do seu perfil.
Se esta superfície for movida horizontalmente, ela acelera o ar em repouso e em torno de si para baixo exercendo uma força vertical ao ar. Reenfatizamos que a contraforça é a sustentação. Este raciocínio qualitativo é aprofundado teoricamente no apêndice 8.1. A aceleração vertical do ar pode ser demonstrada facilmente mediante o uso de um indicador para os movimentos do ar, como se segue.

Experimento em sala de aula para demonstrar a aceleração vertical do ar

Descrevamos inicialmente a construção de um indicador dos movimentos do ar como na Fig. 4. Tomemos uma haste de madeira de $70-100 \mathrm{~cm}$ de comprimento, bem leve porém rígida. Um papel ou uma peça retangular de cartolina de aproximadamente 10 por 10 centímetros é fixada em uma das extremidades da haste. Para que o braço onde se fixou o papel seja bem maior do que o outro, aconselhamos prender um pequeno contrapeso na outra extremidade da haste. Ao ser suspenso pelo centro de massa, o arranjo deve permanecer na horizontal com a face do papel paralela ao chão, podendo mover-se livremente no plano vertical. O modelo da asa pode ser confeccionado com uma tira de cartolina de 20 por 40 centímetros e para isso encurva-se a cartolina segundo a dimensão de 20 centímetros até que as bordas de 40 centímetros se encontrem, quando então, devem ser coladas. Obtém-se a asa, modelando-se cuidadosamente esta peça até formar um perfil como o mostrado na Fig. 3. No início de cada teste o indicador de movimento do ar deve estar em repouso, na horizontal.
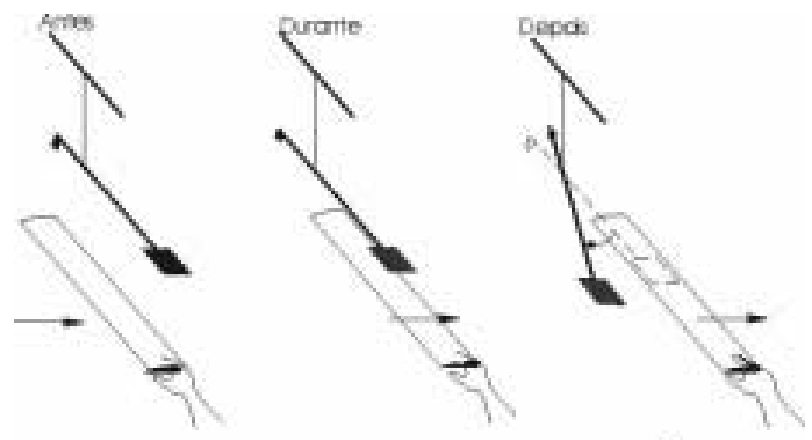

Figura 4. Indicador de movimento do ar, antes, durante e depois da passagem da asa em movimento horizontal abaixo do indicador que, em conseqüência, desloca-se para baixo.

Se o modelo da asa for movido na horizontal, abaixo ou acima do indicador, este se move para baixo, se o ângulo de ataque for positivo. $\mathrm{O}$ indicador permanece quase em repouso, se o ângulo de ataque for próximo de zero, e move-se para cima, se o ângulo de ataque for negativo. Este dispositivo indica a direção e o sentido do movimento do ar. Os seus movimentos serão mais destacados se o ângulo de ataque e a velocidade da asa forem maiores. Depois do deslocamento o indicador tenderá a voltar à posição inicial. Vale a pena salientar, que o indicador detecta a presença de quaisquer movimentos do ar, por isso, ao iniciar cada experimento, 
ventiladores e condicionadores de ar devem ser desligados bem como janelas e portas serem fechadas. Além disso, o modelo da asa deve ser movimentado numa trajetória horizontal retilínea que se inicie distante do indicador a fim de que o escoamento do ar em torno dele se estabeleça de forma estacionária. Estes experimentos simples podem ser demonstrados em sala de aula para esclarecer as relações fundamentais quanto à sustentação da asa.

\section{A sustentação depende do ângulo de ataque}

O fluxo do impulso vertical do ar para baixo, que equivale à sustentação é, em primeira aproximação, proporcional ao ângulo de ataque quando este se situar entre $-10^{\circ}$ e $+20^{\circ}$. Fora desta faixa, o escoamento é turbulento e não segue mais a geometria da asa. Por exemplo, para ângulos superiores a $20^{\circ}$ a sustentação diminui.

\section{A sustentação depende da velocidade}

Podemos mostrar qualitativamente o aumento do movimento vertical do ar devido à velocidade da asa. Teoricamente obtém-se esta relação pelo seguinte raciocínio. Se a velocidade for duplicada, mantendose constantes a geometria da asa e as linhas de escoamento, então duplicarão a massa de ar acelerado para baixo por segundo (fluxo) e a velocidade vertical do ar.

Considerando simultaneamente esses efeitos, a sustentação será quadruplicada, se a velocidade for duplicada. Podemos concluir que, a sustentação é proporcional ao quadrado da velocidade relativa entre o ar e a asa.

\section{A sustentação depende da densidade do ar}

Realmente, todas as forças são proporcionais à massa acelerada. Se as demais condições permanecerem constantes e se somente a massa sofrer variação, então as forças serão proporcionais à densidade. Como sabemos, a uma altitude de $12.000 \mathrm{~m}$ a densidade do ar e a pressão atmosférica só têm um quarto de seus valores na superfície da Terra. Por isso, para um vôo a esta altura o valor da força de sustentação cai para 1/4. Este efeito pode ser compensado duplicando-se a velocidade do vôo o que provocará a quadruplicação da força de sustentação.

\section{Sustentação e atrito induzido}

$\mathrm{O}$ ar acelerado para baixo tem energia cinética que é fornecida pela asa em movimento. A asa que se move na direção horizontal acelerando o ar para baixo, sente consequentemente um atrito que é denominado atrito induzido. Nos laboratórios e nas demonstrações em sala de aula, toma-se como referência, a asa em repouso e o ar em movimento. Esta é a situação dos modelos em túneis de vento. Esta abordagem facilita os cálculos teóricos. Neste caso, a asa causa um desvio do fluxo de ar em torno dela. Podemos também mostrar facilmente o desvio do escoamento para baixo, como se segue:

Experimento em sala de aula para demonstrar o desvio do escoamento para baixo:

Use o jato de ar de um secador de cabelos e o mo- delo de uma asa como o descrito anteriormente. Cole uma tira de papel de seda na borda traseira da asa que funcionará como indicador da direção do fluxo de ar atrás dela. Coloque-a agora no fluxo de ar do secador. Pode-se ver que a direção da tira coincide com a do escoamento. Mudando-se o ângulo de ataque muda-se a direção do escoamento do ar atrás da asa.

Considerando todos estes fatos concluímos que o raciocínio baseado nas leis da mecânica é coerente e explica a sustentação da asa. Só falta a explicação do mecanismo da aplicação das forças à asa, quer dizer, da geração das pressões em torno dela.

\section{Fundamentos da dinâmica dos fluidos}

\section{III.1 Observações gerais}

A dinâmica dos fluidos é baseada nas leis da mecânica Newtoniana como mostrou Euler há quase três séculos. Ele aplicou as leis fundamentais de Newton ao movimento de fluidos em três dimensões e estabeleceu as equações diferenciais do escoamento, as chamadas equações de Euler. Vamos examinar as equações de movimento de um fluido, atendendo às nossas necessidades específicas. Por isso, vamos considerar o fluido ideal. Para simplificar os cálculos limitamos nossa análise a um escoamento estacionário dentro de um tubo de corrente [11]. O tubo pode ser curvo e seu diâmetro pode variar.

Examinemos um elemento de massa $\Delta m=\rho \cdot \Delta V$, sendo $\rho$ a sua densidade e $\Delta V$ o seu volume. Pela segunda lei de Newton a aceleração desta massa é devida a uma força resultante que tem a mesma direção da aceleração. As forças aplicadas à massa $\Delta m$ são decorrentes das diferenças das pressões nas faces opostas do seu elemento de volume $\Delta V$. Veja Fig. 5 .

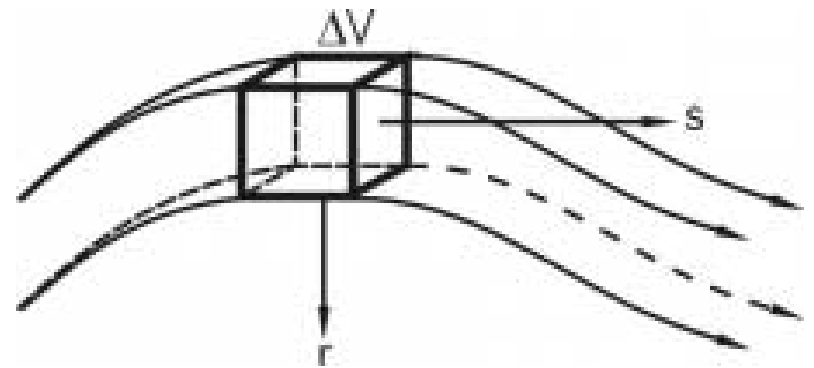

Figura 5. Elemento de volume de um fluido dentro de um tubo de escoamento.

Assim, a aceleração de uma partícula do fluido é causada pelos gradientes de pressão estática. São duas as acelerações principais: a tangencial e a normal com respeito à direção do movimento, indicada pelas linhas do escoamento. 


\section{III.2 Aceleração tangencial e a lei de Bernoulli}

A aceleração tangencial é causada por uma diferença de pressão na direção do movimento. Se a aceleração for positiva a pressão deve ser maior na face posterior do que na da anterior. É esta diminuição da pressão a causa da aceleração. Consequentemente uma velocidade maior numa região de baixa pressão é o efeito provocado pela pressão menor. Se esta relação for bem entendida nunca se pode pensar em usar a velocidade maior como causa da diminuição da pressão. Vale a pena evidenciar este raciocínio qualitativo porque assim se evitam explicações incorretas das aplicações da equação de Bernoulli. O cálculo que segue resulta na lei de Bernoulli.

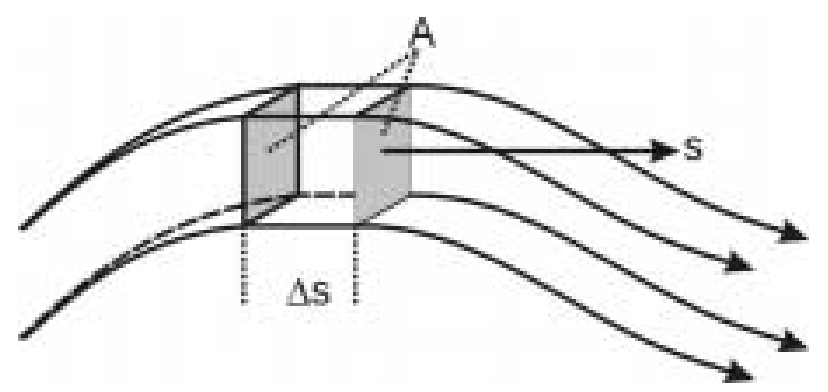

Figura 6. Aceleração tangencial de um elemento de massa de fluido.

Vamos nos referir ao elemento de massa da Fig. 6 . Aplicando a segunda lei de Newton, tem-se:

$$
F=\Delta m \cdot a, \text { em que } a=\frac{d v}{d t} .
$$

Sendo a força na direção $s$ do movimento escrevemos

$$
F=-A \cdot \Delta p=-A \cdot \frac{d p}{d s} \cdot \Delta s
$$

Lembre-se de que a força será positiva se a pressão diminuir, por isso o sinal é negativo. O elemento de massa é:

$$
\Delta m=\rho \cdot A \cdot \Delta s .
$$

Substituídas estas quantidades na Eq. (1), obtemos:

$$
-A \cdot \frac{d p}{d s} \cdot \Delta s=\rho \cdot A \cdot \Delta s \cdot \frac{d v}{d t} .
$$

Dividindo por $A \cdot \Delta s$, e rearrumando os termos, resulta em

$$
-\frac{d p}{d s}=\rho \cdot \frac{d v}{d t} \quad \text { ou } \quad-d p=\rho \cdot \frac{d v \cdot d s}{d t}
$$

Lembrando que $v=d s / d t$ e substituindo-a na expressão acima, encontramos a seguinte equação diferencial:

$$
-d p=\rho \cdot v d v
$$

integrando esta relação entre as posições 1 e 2 do elemento de volume, isto é:

$$
-\int_{1}^{2} d p=\rho \int_{1}^{2} v \cdot d v,
$$

que resulta na equação de Bernoulli, propriamente dita:

$$
p_{1}-p_{2}=\frac{\rho}{2}\left(v_{2}^{2}-v_{1}^{2}\right)
$$

A derivação acima não é tão fácil como aquela comumente presente nos livros-textos que usa a lei da conservação da energia. Mas esta abordagem tem uma vantagem fundamental: ela deixa claro que a velocidade maior é sempre o efeito de pressão menor. Tendo em mente esta relação, evitam-se erros na sua aplicação, especialmente quando uma maior velocidade do fluxo for considerada como causa da pressão menor. Resta ainda um problema: como se produz a diminuição da pressão no escoamento, nas proximidades de um obstáculo, como uma asa? A resposta a esta pergunta está na aceleração normal ao escoamento, a qual passaremos a examinar.

\section{III.3 Aceleração normal}

Para completar a análise das acelerações sofridas pelo fluido temos que considerar a aceleração perpendicular à velocidade, ou seja, a aceleração do elemento de massa do fluido na direção normal ao escoamento, como ilustrado na Fig. 7.

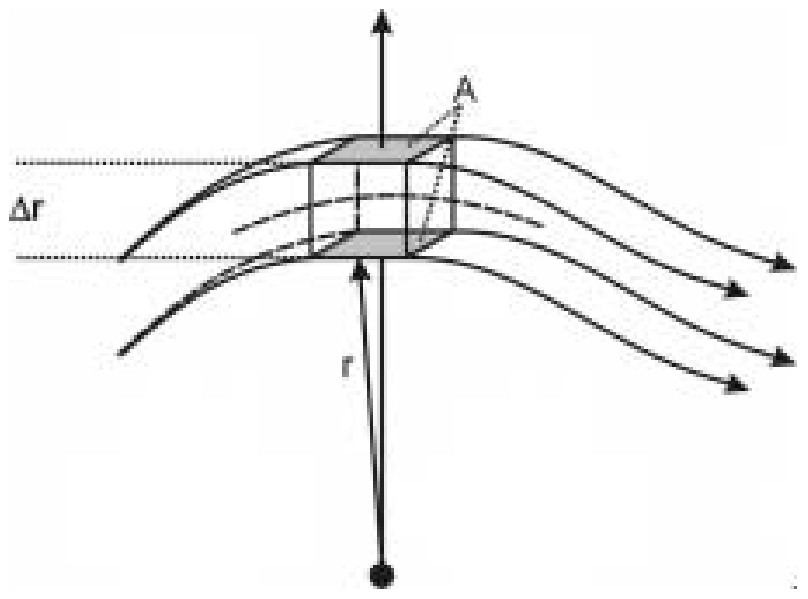

Figura 7. Aceleração normal de um elemento de massa do fluido.

Se o tubo de escoamento for curvo, existe uma aceleração normal direcionada para o centro de curvatura. Esta aceleração só pode existir se uma força em direção ao centro de curvatura for aplicada ao elemento de massa. No nosso caso, a força só pode ser originada das diferenças das pressões nas faces paralelas à linha de escoamento. A pressão na face voltada para o centro de curvatura deve ser menor do que a pressão na face oposta. Qualitativamente, podemos concluir que 
nas condições em que se produz um escoamento curvo, a pressão aumenta na direção oposta ao centro de curvatura da trajetória.

A aceleração perpendicular às linhas do escoamento é importante porque está relacionada a um gradiente da pressão perpendicular a estas mesmas linhas. A demonstração mais simples deste fato é através da rotação de um líquido num recipiente cilíndrico, gerando um escoamento circular com linhas de escoamento também curvas. A superfície do fluido sobe proporcionalmente ao quadrado da distância ao eixo de rotação, mostrando um aumento da pressão relativamente a um nível constante. Uma aplicação deste efeito é a máquina centrifugadora. Para uma análise quantitativa partimos novamente da equação de movimento de Newton, Eq. (1).

Representemos o eixo normal à linha de escoamento direcionado para fora do centro por $r$, como na Fig. 7 .

A força aplicada ao elemento de massa é:

$$
F=-A \cdot \frac{d p}{d r} \cdot \Delta r
$$

O sinal negativo é devido ao fato de que um gradiente positivo gera uma força direcionada para o centro de curvatura (direção negativa).

Como já sabemos a massa é dada por

$$
\Delta m=\rho \cdot A \cdot \Delta r .
$$

Substituindo estas quantidades na Eq. (1), obtemos que

$$
-A \cdot \frac{d p}{d r} \cdot \Delta r=\rho \cdot A \cdot \Delta r \cdot \frac{d v}{d t}
$$

oul

$$
\frac{d p}{d r}=-\rho \cdot \frac{d v}{d t}
$$

Neste caso, sabemos que a aceleração normal é dada por

$$
\frac{d v}{d t}=-\frac{v^{2}}{r}
$$

em que $r$ é o raio de curvatura.

Substituindo esta expressão em (11), obtemos a equação diferencial que descreve a relação entre o gradiente de pressão na direção $r$ em função do raio de curvatura da linha de escoamento e da velocidade do fluxo do fluido,

$$
\frac{d p}{d r}=\rho \cdot \frac{v^{2}}{r} .
$$

Infelizmente esta equação não tem solução fácil, pois as pressões são obtidas através de uma integração ao longo de trajetórias perpendiculares às linhas de escoamento. A solução depende do conhecimento das distribuições de velocidade $v$ e dos raios de curvatura $r$ das linhas de corrente no campo do escoamento.
Existe, apesar disso, um caso em que a solução analítica pode ser facilmente obtida. Se o líquido estiver girando, como no caso de um cilindro girante, sua superfície adquire a forma de um parabolóide. A altura do líquido funciona como um manômetro, indicando a pressão referente a um nível fixo. Para uma velocidade angular uniforme $\omega$, a velocidade do fluido a uma distância $r$ do eixo de rotação é dada por

$$
v=r \cdot \omega
$$

Substituindo $v$ na Eq. (13) acima, resulta em

$$
\frac{d p}{d r}=\rho \cot \frac{r^{2} \cdot \omega^{2}}{r}
$$

cuja solução é

$$
p=\rho \cdot \omega^{2} \cdot \frac{r^{2}}{2}
$$

A pressão, e portanto a altura da superfície, é proporcional ao quadrado da distância $r$ ao eixo como já foi mencionado. Esta relação vale também para máquinas centrifugadoras.

Inexplicavelmente, os livros-textos não tratam da aceleração normal num escoamento. Por isso, a existência de gradientes de pressão perpendiculares às linhas do escoamento é omitida também. Esta omissão não ocorre nos livros técnicos de dinâmica dos fluidos em tubos curvos. A ausência da análise dos gradientes de pressão normais ao escoamento tem um resultado desastroso. Sem ela é literalmente impossível entender a geração das pressões menores num escoamento. Para analisar a produção das pressões menores temos antes que explicar o efeito Coanda.

\section{III.4 Efeito Coanda}

Se um obstáculo for inserido no fluxo de um fluido o seu escoamento próximo às superfícies limitantes acompanha as suas formas se as superfícies forem suavemente curvas. Exemplos são as asas dos aviões, os corpos dos pássaros e todas as formas chamadas aerodinâmicas. Este comportamento de um fluido é chamado de efeito Coanda em homenagem ao engenheiro inglês que o descobriu e analisou. Na Física, um escoamento deste tipo é denominado laminar. Se o obstáculo tem curvas abruptas ou cantos, o escoamento não segue mais a superfície, formando vórtices. Neste caso tem-se um escoamento turbulento. O exemplo clássico do efeito Coanda é um jato de fluido lançado sobre uma superfície plana, soldada a um setor cilíndrico (Fig.8). O escoamento não se separa imediatamente da superfície do cilindro mas a segue até certo ponto onde então começa a separação. 

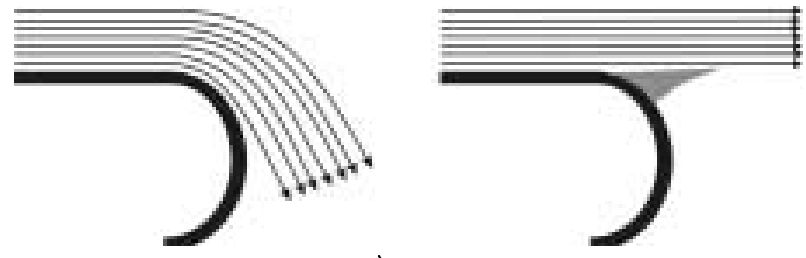

Figura 8. Efeito Coanda: À esquerda efeito Coanda, à direita um experimento imaginário.

Podemos entender o efeito Coanda considerando a viscosidade do fluido. Na Fig. 8, à direita, mostramos o estado inicial de um experimento imaginário. Um jato de fluido é lançado sobre a parte plana da superfície na hipótese de viscosidade nula. Devido à própria inércia o jato tenderia a manter a direção do movimento ao se deslocar na parte curva da superfície cilíndrica. No entanto, considerando-se agora a viscosidade, mesmo que seja mínima, o fluido entre o jato e o cilindro vai ser removido provocando nesse local uma diminuição da pressão, o que ocasiona o encurvamento do fluxo. Este fato o leva a acompanhar a superfície do cilindro e faz surgir um gradiente de pressão e uma aceleração, ambos normais às linhas de corrente do fluido. Este experimento virtual mostra não só a origem deste comportamento do fluido mas também a importância de ter um mínimo de atrito ou viscosidade para os escoamentos estacionários em torno de obstáculos com formas aerodinâmicas. Sendo este comportamento fundamental para a explicação da sustentação da asa, torna-se indispensável um mínimo de viscosidade ou atrito.

\section{III.5 Geração das pressões}

Podemos demonstrar experimentalmente em sala de aula a geração de pressões maiores e menores no escoamento de fluidos através de um arranjo experimental bastante simples: um jato de ar de um secador de cabelos e um manômetro bastante sensível. (Veja a Fig. 9). Nos apêndices 2 e 3 estão descritos os detalhes da confecção dos dispositivos que usaremos a seguir. Inicialmente podemos demonstrar que a pressão estática dentro do jato de ar é igual à pressão atmosférica. Existem textos que dizem que, devido à lei de Bernoulli, a pressão dentro do jato é menor do que fora. É um equívoco. A pressão estática é a atmosférica, dentro e fora do jato, o que pode ser averiguado medindo-as com o manômetro sensível. Veja Fig. 23 no apêndice.

\section{III.5.1 Geração das pressões devido ao desvio de escoamento}

Desviamos o escoamento inserindo uma superfície curva em seu fluxo como mostra o esquema na Fig. 9.

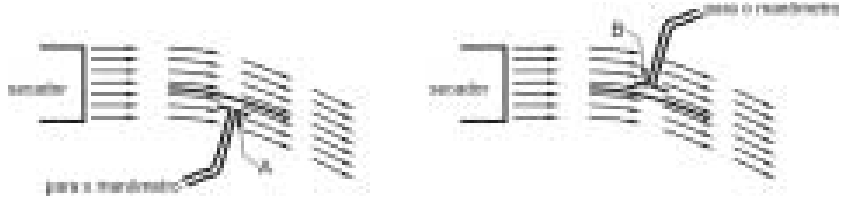

Figura 9. Desvio de um escoamento do ar. Medição da pressão estática abaixo (A) e acima (B) da superfície.

Geração de pressão maior acelerando o escoamento para fora da superfície.

Analisemos, inicialmente, o escoamento abaixo da superfície. Na sua face inferior o escoamento não tem alternativa a não ser seguir a superfície inserida, porque não pode penetrá-la. Assim, o escoamento tem que ser curvo para baixo. Como mostramos anteriormente, o escoamento curvo tem um gradiente de pressão que diminui a partir da superfície para fora até atingir a pressão atmosférica. A pressão perto da superfície é, consequentemente, maior que a pressão ambiente. Podemos, experimentalmente, demonstrar e medir a pressão maior abaixo da superfície no ponto A da Fig. 9, usando um manômetro sensível, como indicado. Em outras palavras: o jato de ar tem inércia e, para acelerar o escoamento para baixo, a superfície tem que lhe aplicar uma força no mesmo sentido, correspondendo a um aumento da pressão.

Geração de pressão menor acelerando o escoamento em direção à superfície.

Desta vez analisamos o escoamento acima da superfície. Veja o ponto (B) da Fig.9. Neste caso, lembremos do efeito Coanda. Por causa dele o escoamento segue a superfície curva. Como mostramos anteriormente, o escoamento curvo tem um gradiente de pressão, sendo que, desta vez, ela aumenta a partir da superfície para fora até atingir o valor final igual à pressão atmosférica local. A pressão no fluido perto da superfície é, por causa disso, menor.

Podemos portanto demonstrar e medir experimentalmente a pressão menor acima da superfície no ponto B.

Em outras palavras, o escoamento gera a pressão menor devido a sua própria inércia. Se o ar mantivesse seu movimento na direção original ele se afastaria da superfície, gerando assim um vácuo. Mas antes que isso aconteça, reduz-se à pressão entre o jato e a superfície, gerando por isso um gradiente de pressão necessário para acelerar o ar para baixo.

\section{III.5.2 Origem da velocidade maior acima da su- perfície superior}

Partindo do fato já explicado de que a pressão na superior é menor, podemos agora entender porque na superfície superior da asa a velocidade é maior. Ao entrar em uma região de menor pressão o ar é acelerado paralelamente ao deslocamento, ganhando maior velocidade. Vale a lei de Bernoulli. Mas desta vez é claro que a pressão menor é a causa da velocidade maior. Então 
a lei de Bernoulli é válida mas a interpretação correta é diferente da usada nos livros-textos. As diferenças de pressão são causadas pelo desvio do escoamento. Só em função destas pressões as velocidades se modificam.

\section{Análise das curvaturas do es- coamento}

Se o tubo de corrente for curvo, temos gradientes de pressão perpendiculares à direção do escoamento. Este raciocínio é a chave para entender o mecanismo que gera a distribuição das pressões em torno dos obstáculos.

Dentro de certos limites, um escoamento tende a acompanhar as superfícies suavemente curvas o que é explicado pelo efeito Coanda. Se uma superfície curva forçar um escoamento a desviar-se, gera-se uma pressão maior, se o escoamento for acelerado para fora da superfície, e menor, se no sentido da superfície. Ambos os casos são vistos a partir da superfície do obstáculo.

Por isso a análise das curvaturas preponderantemente nas vizinhanças dos objetos inseridos nos fluxos de fluidos nos permite prever as distribuições de pressão. Podemos evidenciar o potencial da análise da curvatura das linhas de escoamento de um fluido nas vizinhanças de um obstáculo nele inserido, mostrando a previsão de distribuição das pressões sobre diferentes pontos de sua superfície.

\section{IV.1 Pressões na superfície da asa}

As análises e os resultados que seguem estão presentes na literatura [15] e podem ser comprovados experimentalmente em sala de aula com um jato de ar de um secador de cabelos, um manômetro sensível e um modelo de asa como mostra a Fig. 10a. Suas confecções estão descritas detalhadamente nos apêndices 2 e 3. Examinemos as curvaturas de um escoamento em torno de um perfil simétrico com ângulo de ataque zero. Veja Figs. 10a e 10b.

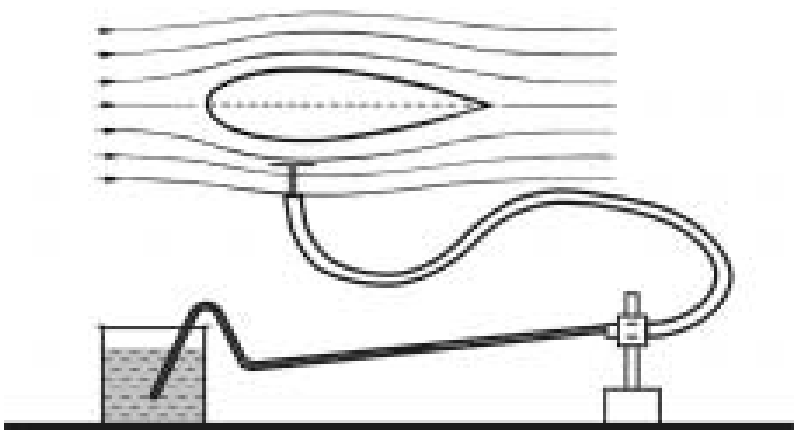

Figura 10a. Asa de perfil simétrico sem ângulo de ataque, suas linhas de escoamento e medição da pressão usando um manômetro sensível.

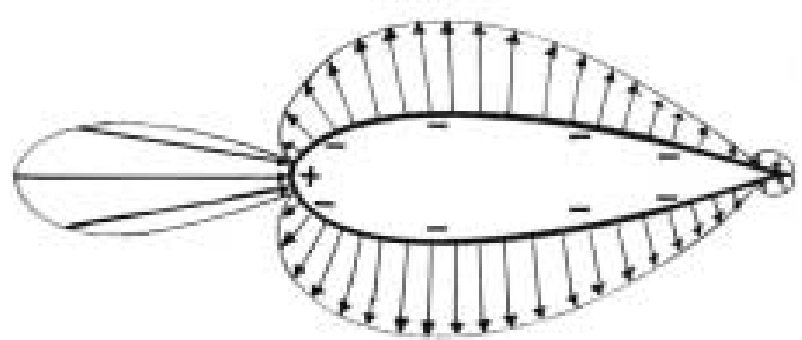

Figura 10b. Distribuição das forças devida à pressão sobre o perfil simétrico.

Se o escoamento for acelerado para fora, visto a partir da superfície, a pressão aumenta. Isto é o que ocorre na frente do perfil da asa. Por isso esperamos e realmente observamos a pressão aumentada na frente da asa, Fig.10b. Ao longo do perfil o escoamento é curvo para dentro acompanhando o desenho da asa. Consequentemente, podemos prever e constatar uma pressão reduzida ao longo do perfil causando uma força para fora em suas duas faces. Sendo todas as forças iguais e opostas elas se compensam inteiramente. Neste caso, não há sustentação. Apesar disso, podese ter sustentação com uma asa simétrica desde que o ângulo de ataque seja positivo. O escoamento continua seguindo também a forma do perfil, gerando uma curvatura maior na parte superior do que na parte inferior. As forças para cima e para baixo não se anulam mais, surgindo uma força resultante para cima.

Analisemos agora as curvaturas do escoamento num perfil onde a superfície superior é como a do exemplo acima e a inferior quase plana. (Figs.11a e 11b).

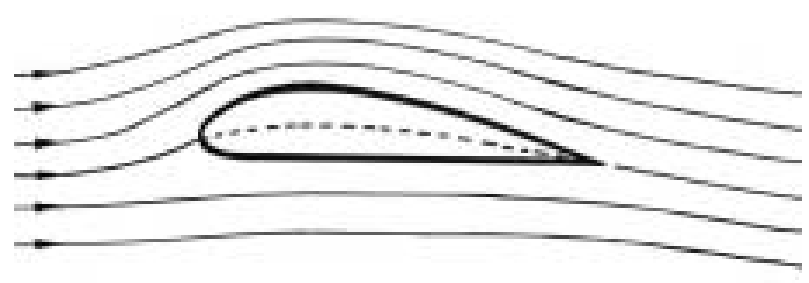

Figura 11a. Perfil de uma asa com a face inferior quase plana e suas linhas de corrente.

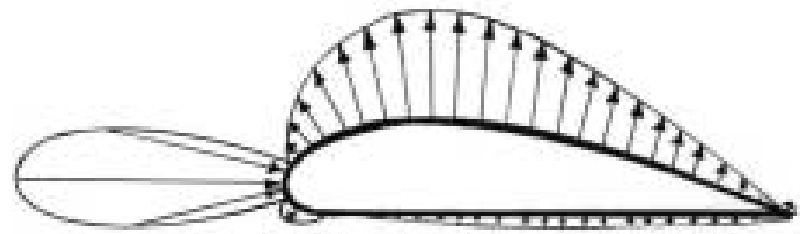

Figura 11b. Distribuição das forças devidas às pressões.

Na superfície superior tudo permanece como no caso anterior. A força resultante para cima mantém-se portanto a mesma. Como a superfície inferior é quase plana, as pressões são praticamente as mesmas de um escoamento não perturbado, não gerando forças significativas para baixo. O resultado geral é uma força dirigida para cima. Neste caso existe sustentação. 
Finalmente analisemos um aerofólio usado por aviões de baixa velocidade cujo perfil possui uma superfície inferior ligeiramente curva. (Figs.12a e 12b).

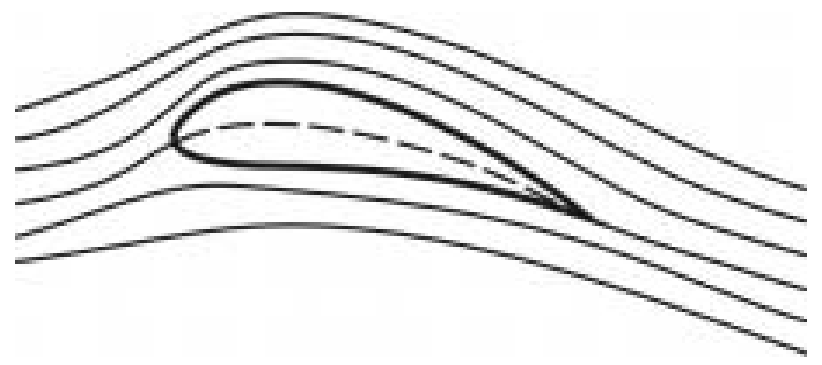

Figura 12a. Perfil de uma asa para baixas velocidades com face inferior ligeiramente curva e suas linhas de correntes.

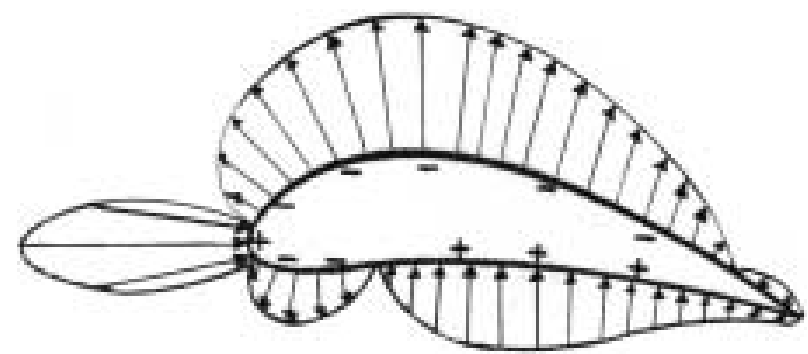

Figura 12b. Distribuição das forças devidas às pressões em função da curvatura das superfícies.

Na superfície superior, nem a curvatura nem o comportamento do escoamento foram alterados significativamente. Na superfície inferior, agora um pouco mais curva, o comportamento do fluxo de ar se modifica. Devido à curvatura ele é acelerado para fora por parte preponderante da região posterior da superfície, gerando ai um aumento da pressão que contribui para a sustentação. Na parte dianteira da asa, no caso de um ângulo de ataque próximo de zero [14], pode até existir uma estreita região onde a curvatura possui o sinal oposto acelerando o escoamento para cima e gerando assim uma pequena pressão negativa diminuindo a sustentação (Fig.12b). Estes exemplos explicam porque a contribuição da superfície superior é sempre maior do que a da inferior, variando em função da geometria do aerofólio e do ângulo de ataque.

\section{IV.2 Outras aplicações da análise das cur- vaturas}

\section{IV.2.1 Vento passando sobre um morro}

Se o vento passa sobre um morro, como mostra a Fig. 13, ele acompanha a sua superfície. A variação do escoamento ocorre essencialmente nas linhas de correntes próximas ao morro. Para alturas bem maiores, comparadas com a altura do morro, o fluxo permanece horizontal e a pressão é a atmosférica. Analisemos o escoamento do ar nas proximidades dos pontos A, B e C, marcados na Fig. 13.

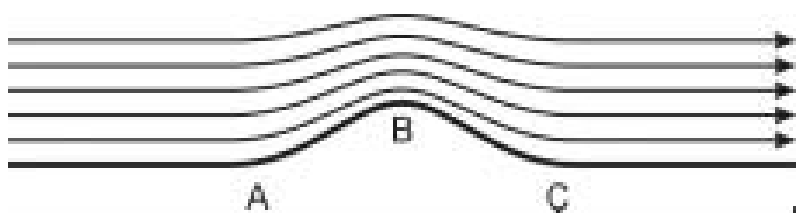

Figura 13. Linhas de corrente de um escoamento sobre um morro.

Nas vizinhanças do ponto A, a superfície acelera o ar para fora, na direção perpendicular a si mesma. Esta aceleração, no entanto, decai à medida que se afasta do ponto $\mathrm{A}$, ao longo da normal, até desaparecer, quando o escoamento volta a ser horizontal e a pressão a ser a atmosférica. Assim é gerada no pé do morro uma região de maior pressão.

Nas vizinhanças do ponto $B$, a parte mais alta do morro, acontece o fenômeno inverso: para seguir a forma da superfície o ar é acelerado para baixo. Como vimos na explicação do efeito Coanda, devido a inércia do ar e a forma da superfície a seguir, produz-se uma redução da pressão nesta região.

Nas vizinhanças do ponto $\mathrm{C}$ o fenômeno é semelhante ao que ocorre em A. Realmente, passado o topo do morro, o ar acompanha a sua encosta na direção de $\mathrm{C}$, gerando neste ponto, devido à curvatura, uma pressão maior.

Podemos demonstrar o raciocínio acima com um arranjo experimental de fácil montagem, usando um manômetro sensível, o jato de ar de um secador de cabelos e um modelo de morro com dimensões adequadas (Apêndices 2 e 3).

\section{IV.2.2 Vaporizador e a pressão dentro de um jato de ar}

No caso do vaporizador, um jato de ar bem forte é lançado sobre um orifício de um tubo fino cuja outra extremidade está imersa em um fluido. A pressão reduzida no orifício provoca a sução do fluido.

O raciocínio usado para analisar a passagem do vento por um morro pode ser aplicado ao vaporizador para explicar o seu funcionamento. A Fig. 14a mostra as linhas de um escoamento em torno de um obstáculo como o de uma ponta de prova feita com um tubo de vidro. O fluido não pode penetrar o vidro e é desviado. $\mathrm{Na}$ extremidade do tubo a curvatura é semelhante à do escoamento no ponto B do exemplo anterior. O fluxo de ar é acelerado para baixo e por causa disso tem a pressão reduzida neste ponto. Para demonstrar isso, basta colocar a ponta de prova do nosso manômetro sensível, sem o disco colado, no jato de ar do secador. Fica bem claro que a redução da pressão é causada pela curvatura do escoamento na extremidade da ponta de prova. A Fig. 14b mostra a mesma ponta de prova do manômetro, agora com um disco perfurado e nela colado, indicando que o escoamento não é curvado acima 
do disco, não causando, por isso, variações da pressão. Conseqüentemente, uma medição da pressão, dentro de um escoamento, realizada com uma ponta da prova sem disco furado, produz resultados errados.

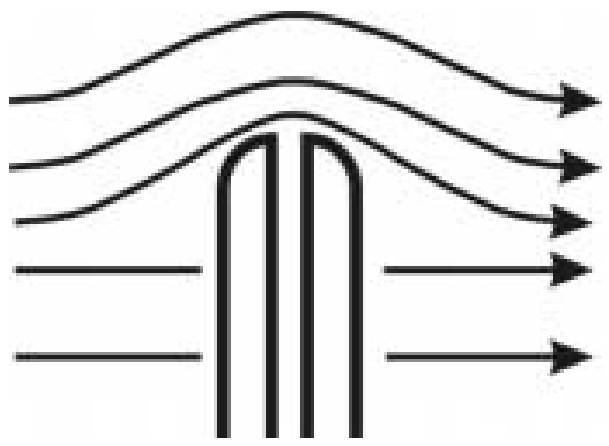

Figura 14a. Escoamento em torno de uma ponta de prova sem o disco com perfuração central, reproduzindo o esquema do vaporizador.

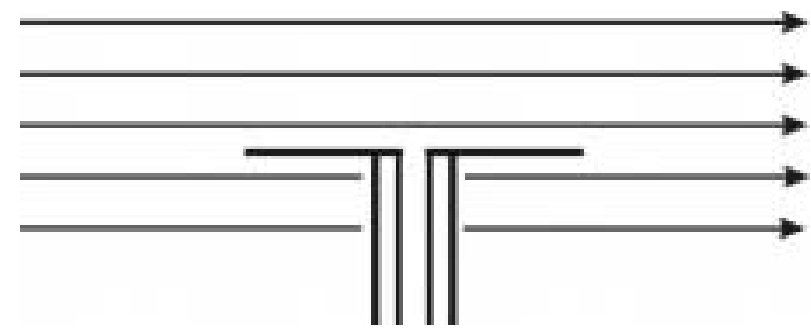

Figura 14b. Escoamento em torno de uma ponta de prova com o disco perfurado e colado ao tubo.

Com a ponta de prova com disco podemos mostrar que a pressão estática é a mesma tanto fora quanto dentro do jato de ar produzido pelo secador [13]. Veja Fig. 23 no apêndice. Neste caso a lei de Bernoulli não pode ser usada, porque as condições para a sua aplicação não são dadas, isto é: a ausência do atrito ou da viscosidade. Na realidade, com raras exceções como superfluidos, sempre temos viscosidade nos fluidos. A aplicação das equações referidas só é permitida se o efeito do atrito for negligenciado. Isto significa, que as acelerações devem ser causadas pelos gradientes de pressão e não pelo atrito. No caso do jato de ar do secador toda a desaceleração do escoamento é causada pelo atrito, quer dizer, pela viscosidade do ar.

Consequentemente, neste caso a lei de Bernoulli não tem aplicação e, se for aplicada, conduz a erros.

\section{IV.2.3 Bola flutuando num jato de ar}

$\mathrm{O}$ experimento com a bola de pingue-pongue flutuando num jato de ar é uma demonstração bem atraente. A explicação, usando a lei de Bernoulli, é imprópria porque o interior do jato de ar tem a mesma pressão estática que fora dele. A força para dentro é devida ao escoamento em torno da bola. Na situação ilustrada na Fig. 15, a bola saiu do centro do jato porque ele foi levemente inclinado. Consequentemente, existem mais linhas de corrente do fluido à esquerda e acima da bola (ponto $\mathrm{A}$ ) do que à sua direita e abaixo (ponto B). Realmente, existe mais curvatura nas linhas de corrente do fluido nas vizinhanças do ponto A do que do ponto B. Assim, a pressão é menor no ponto A

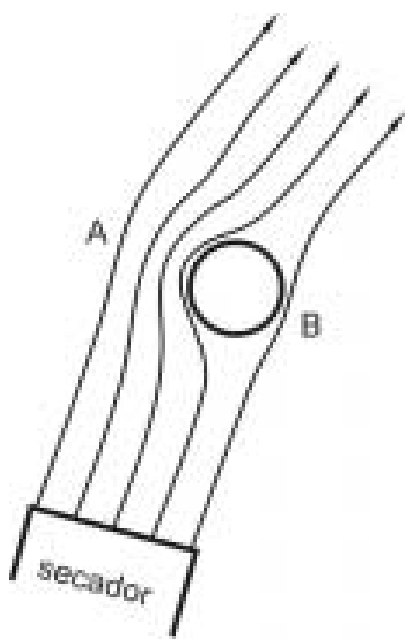

Figura 15. Bola flutuando em um jato de ar produzido por um secador de cabelos.

\section{IV.2.4 Vendaval}

Um vendaval pode causar danos nas casas atingidas. Por isso vale a pena analisar o fenômeno para saber minimizar seus efeitos danosos. A Fig. 16 mostra o desenho de uma casa dentro de um fluxo de ar.

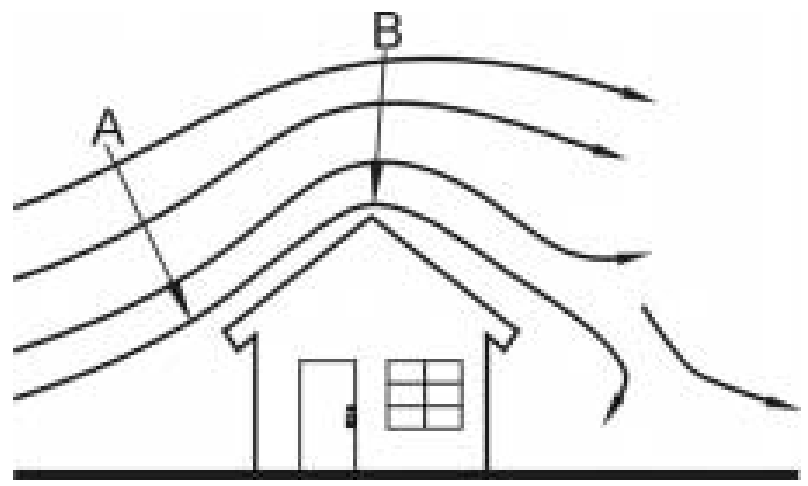

Figura 16. Escoamento do ar sobre uma casa durante um vendaval.

O escoamento pode ser considerado aproximadamente laminar no lado da casa que recebe o vento. No lado oposto o fluxo vai ser turbulento, sem linhas de corrente estacionárias. Pela curvatura das linhas de corrente na região do ponto $\mathrm{A}$, podemos prever um aumento da pressão no lado do vento. O fluxo é acelerado para cima. No teto da casa, a curvatura das linhas é invertida. O escoamento é acelerado para baixo. Por isso prevemos uma pressão reduzida no teto. No lado da casa oposto ao vento, o escoamento é turbulento e, consequentemente, não podemos prever exatamente a pressão. Mas podemos assumir que ela não pode ser 
maior do que a pressão no teto. Uma aproximação razoável é supor que esta pressão seja quase igual à pressão reduzida no teto. O perigo para o telhado são as forças para fora. A força que se aplica ao telhado é causada pelas diferenças entre as pressões dentro e fora da casa. Então qual é a pressão dentro da casa? Se todas as portas e todas as janelas forem fechadas hermeticamente a pressão dentro da casa será indefinida. Se uma porta ou uma janela for aberta, a pressão dentro atinge a pressão do lado de fora da porta ou janela. Se uma porta no lado do vento for aberta a pressão dentro da casa vai ser maior. Se a porta do lado oposto ao vento for aberta, a pressão vai ser menor.

Observando estes fatos recomenda-se fechar, minimamente, as portas e janelas no lado do vento e, para reduzir a pressão dentro, abrir portas e janelas do lado oposto ao vento.

Esta distribuição das pressões pode ser demonstrada experimentalmente com um modelo adequado de uma casa, usando o secador de cabelos e o manômetro sensível.

\section{IV.2.4 Carro}

A Fig. 17 mostra o escoamento em volta de um carro em movimento. Este caso é também semelhante ao do morro. Pelas curvaturas do escoamento, pode-se prever o aumento da pressão na frente do carro, onde o ar é acelerado para cima (região A) e sua diminuição no teto, onde o ar é acelerado para baixo (região B).

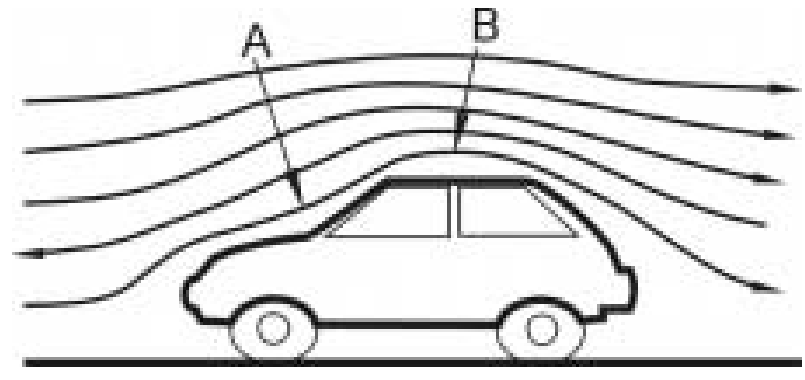

Figura 17. Escoamento sobre um carro em movimento.

\section{Escoamento e sistemas de cir- culação}

A respeito do escoamento total, temos que acrescentar o seguinte quadro: se existirem regiões na asa com maior pressão acima do que abaixo dela, o ar realizará um movimento lateralmente para fora. Já o ar fora da asa acelera-se um pouquinho para cima. Surge assim uma circulação atrás da asa como mostra a Fig. 20. $\mathrm{s}$ vezes os pássaros se utilizam deste movimento do ar para cima que ocorre na extremidade da asa, voando ao lado mas um pouco atrás do companheiro. Quando as andorinhas fazem longos percursos elas voam assim.

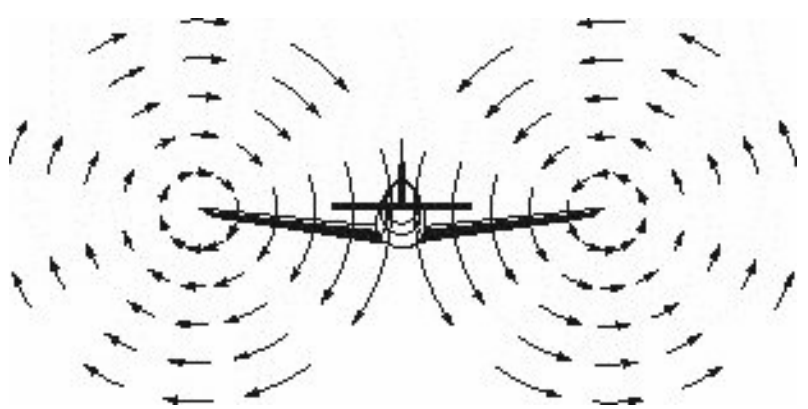

Figura 18. Circulação em volta da asa.

No total, os movimentos para baixo são preponderantes. Os sistemas de circulação são bastante estáveis e se movem para baixo durante longo tempo após a passagem do avião

\section{Notas sobre a história das ex- plicações da sustentação}

Em 1889, Otto Lilienthal deu uma explicação correta, embora qualitativa da sustentação [16]. Com referência à Fig.18, quando comparava o desvio do escoamento por uma superfície plana e curva ele disse:

$O$ ar que passa pelas superfícies é acelerado para baixo em ambos os casos. $O$ desvio para baixo ocorre mais bruscamente na frente da superfície plana causando turbulência.

O desvio na superfície curva é diferente.

O escoamento do ar que passa por ela é dirigido gradualmente da direção horizontal para baixo. O escoamento ganha uma componente vertical na velocidade sem impacto súbito. Por isso o desvio do escoamento ocorre com menos turbulência. O impulso vertical é responsável pela sustentação da asa.

Niermann (1989) [17] cita que ao invés de se elaborar mais esta explicação, ela foi substituída nos livros textos dos Estados Unidos e da Alemanha na década de vinte do século passado pela explicação convencional errada. Até a lei de Bernoulli, que antes quase nunca era tratada nos livros textos de Física, passou a ser introduzida com o fim de servir como base da explicação. Não se sabe ainda com certeza como ocorreu esta substituição e quais foram os motivos. Só podem ser feitas conjecturas na tentativa de entender como tal erro possa ter sido cometido e legitimado na literatura. 


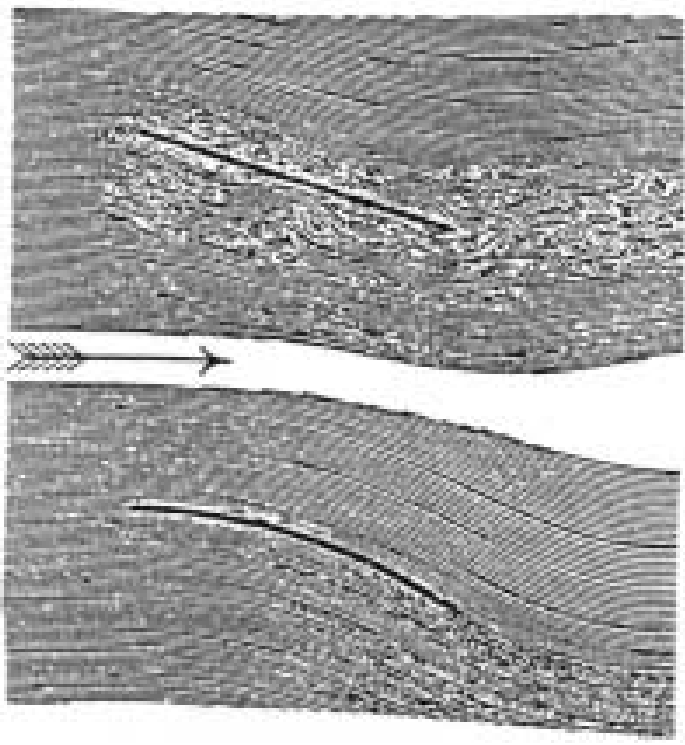

Figura 19. Desenho de Lilienthal [15] de um escoamento.

Para o teórico, o cálculo da distribuição da pressão na superfície de uma asa é importante. Para isso é necessário conhecer quantitativamente o escoamento em torno de seu perfil. Uma boa aproximação é calcular o escoamento potencial em torno de um cilindro e superpor uma circulação. Pelo método das transformações conformes um cilindro pode ser transformado num aerofólio. Nesta transformação o escoamento continua obedecendo às equações de Euler $[11,14]$. O valor da circulação é obtido sob a condição de que o escoamento na parte posterior da asa acompanhe o seu perfil.

Conhecido o escoamento pode-se determinar a distribuição de duas maneiras:

i) integrar os gradientes de pressões em linhas ortogonais em relação ao escoamento, começando por pontos arbitrários da superfície da asa.

ii) calcular diretamente as pressões usando as velocidades do escoamento já determinadas pela lei de Bernoulli.

A segunda maneira é mais fácil e foi usada por teóricos como Prandtl [12], von Kárman [13] e outros no início do século XX. Então se pode entender a tendência de usar esta distribuição de velocidades também como causa das pressões, o que é, obviamente errado. Como já foi dito não é possível explicar por este método como a asa causa as diferenças de velocidade no ar. A fragilidade desta explicação foi percebida desde o seu surgimento quando se buscava uma causa para explicar como o ar escoa com maior velocidade acima da asa. A mais freqüentemente usada era o raciocínio baseado numa comparação entre os caminhos do ar acima e abaixo da asa e a hipótese de que partículas do ar que estavam juntas e foram separadas pela asa deverão se juntar novamente atrás dela. A origem deste raciocínio equivocado pode estar em alguns desenhos da época como mostra a Fig. (19)
Nesta Fig. 20 as linhas pontilhadas mostram partículas vizinhas do ar. Este desenho de Prandtl [18] de 1921 deveria mostrar o efeito do atrito. As partículas do ar bem perto da asa foram retardadas. Este desenho sugere que, não obstante o efeito do atrito, partículas do ar que estavam juntas antes da asa passar se juntam depois, atrás dela. Isso é errado como mostra a Fig. 2. Desenhos deste tipo talvez tenham suscitado a falsa hipótese. Esta argumentação não pretende ser conclusiva.

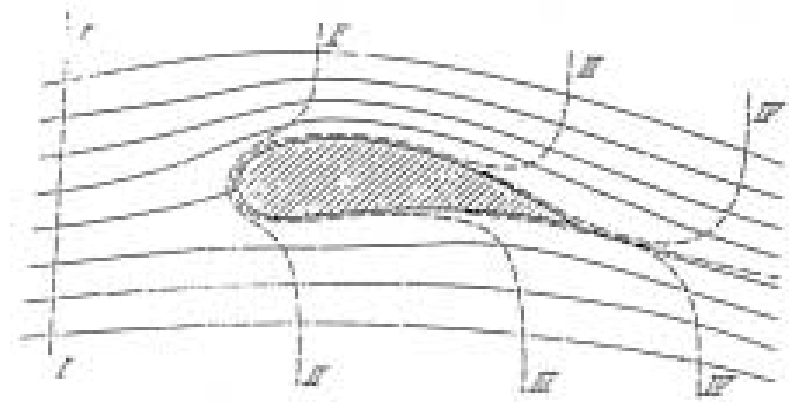

Figura 20. Posições das partículas do ar vizinhas nos tempos de I até IV, Prandtl[18].

\section{Conclusão}

$\mathrm{Na}$ explicação convencional da sustentação da asa, causa e efeito estão trocados. A maior velocidade do ar acima da asa não é a causa mas sim a conseqüência de uma pressão menor nesta região.

A grosso modo, o efeito preponderante da asa é a aceleração do ar para baixo. Para entender os detalhes devemos observar as acelerações normais que causam gradientes de pressão ortogonais às linhas de corrente cujas formas são determinadas pela configuração e posição da asa. Infelizmente, a maioria dos livros-textos de Física só menciona as acelerações tangenciais. Se a dinâmica dos fluidos for baseada na análise completa das relações entre acelerações e gradientes de pressão muitos erros a respeito das aplicações da lei de Bernoulli poderiam ser evitados. A relação do gradiente normal da pressão com a curvatura das linhas do escoamento em combinação com o efeito Coanda é a chave para o entendimento da geração das pressões na superfície de um obstáculo. Vista da superfície do obstáculo a pressão aumenta se o escoamento for empurrado para fora e diminui se o escoamento for acelerado para dentro. Assim a análise da curvatura das linhas do escoamento nas vizinhanças do obstáculo nos dá a distribuição das pressões sobre sua superfície. Chamamos a atenção dos leitores para a explicação da sustentação da asa, acima exposta, pois acreditamos que ela reflete um entendimento mais apropriado do fato. 


\section{Apêndices}

\section{Circulação e sustentação - Significado da Fórmula de Kutta-Joukowski}

Já mencionamos que a sustentação e a circulação estão relacionadas, como mostraram pela primeira vez Kutta e Joukowski no início do século XIX. Em homenagem a seus trabalhos a fórmula de sustentação é denominada fórmula de Kutta-Joukowski.

A sustentação de um trecho da asa de envergadura de 1 metro é (fórmula de Kutta-Joukowski [12]):

$$
F=\rho \cdot v \cdot \Gamma
$$

Sendo $F$ a força da sustentação, $\rho$ a densidade do ar, $v$ a velocidade relativa do escoamento e $\Gamma$ a circulação definida como

$$
\oint \vec{v} \cdot d \vec{s}
$$

Segundo as equações de Euler, a circulação não depende do caminho de integração. Por isso em um escoamento, tem-se que circular

$$
v=\frac{\Gamma}{2 \pi \cdot R} .
$$

A velocidade é proporcional ao inverso da distância $R$ ao centro da circulação e a direção dela é perpendicular ao raio. Pode-se mostrar que todas as superposições de escoamentos potenciais com escoamentos circulares são soluções das equações de Euler. Na dinâmica dos fluidos determina-se o escoamento estacionário em torno de uma asa a partir do escoamento potencial calculado pelas equações de Euler, superpondo a ele escoamentos circulares com centros na linha média do perfil da asa sob a condição de que a superposição resulte num escoamento paralelo à superfície. Assim se constrói o escoamento. É possível deduzir deste escoamento as velocidades e, mediante a lei de Bernoulli, determinam-se as distribuições de pressão, a partir das quais calcula-se a sustentação.

Assim aparecem a circulação e a lei de Bernoulli no cálculo da sustentação. Mas, nestes cálculos, a relação física entre circulação e sustentação é quase oculta. Por causa disso mostramos uma derivação da formula de Kutta- Joukowski seguindo o raciocínio de Prandtl [12].

Esta fórmula relaciona a mudança do impulso vertical de um escoamento com a sustentação. Fica claro que a asa muda o fluxo de impulso do escoamento gerando a sustentação e a circulação.

Na Fig.(21) apresentamos um corte de uma asa num volume de controle. Na teoria da dinâmica dos fluidos existe um lema: A força aplicada a um corpo é dada pela integral de superfície da pressão e a variação do fluxo de impulso através do volume de controle.

Vamos considerar o caso bidimensional e considerar a envergadura da asa infinita.

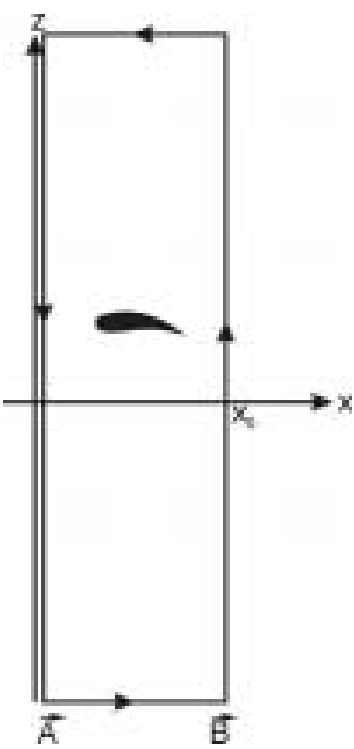

Figura 21. Asa dentro de um volume de controle.

A fim de determinar a variação de fluxo de impulso vertical referimo-nos ao volume de controle formado por duas superfícies A e B perpendiculares à direção original do escoamento (Fig. 22).

Referimo-nos a um tubo de escoamento com espessura $\Delta z$ e de envergadura $y$ (direção perpendicular ao plano da pagina) que corta as superfícies A e B. O fluxo da massa de ar que é a massa de ar que passa na unidade de tempo pela superfície B pode ser escrito como

$$
\Delta \dot{m}=\rho \cdot \Delta z \cdot y \cdot v_{x}
$$

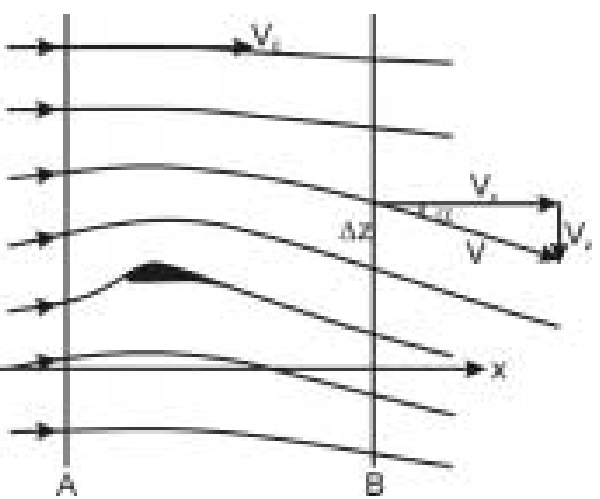

Figura 22. Asa dentro de um volume de controle com superfície na frente $\mathrm{A}$, e atrás, $\mathrm{B}$.

O fluxo do impulso vertical na direção z é:

$$
\Delta \dot{A}=\Delta \dot{m} \cdot v_{z}
$$

Substituindo o fluxo de massa nessa equação. obtemos:

$$
\Delta \dot{I}=\rho \cdot \Delta z \cdot y \cdot v_{x} \cdot v_{z}
$$

Para se obter o fluxo total que passa pela superfície B temos que integrar: 


$$
I_{B}=\rho \cdot y \cdot \int_{-}^{\infty} \infty v_{z} \cdot v_{x} \cdot d z
$$

Usando a aproximação para $\alpha$ pequeno, $v_{x}=v_{0} \cdot \cos \alpha \approx$ $v_{0}$, onde $v_{0}$ é a velocidade do escoamento, temos que

$$
\dot{I}_{B}=\rho \cdot y \cdot v_{0} \int_{B} v_{z} d z .
$$

Para a superfície A podemos proceder de forma análoga. Então a variação do fluxo de impulso é dada pela diferença

$$
\dot{I}_{A}-\dot{I}_{B}=\rho \cdot y \cdot v_{0} \cdot\left[\int_{B} v_{z} \cdot d z-\int_{A} v_{z} \cdot d z\right]
$$

Admitindo o percurso de integração fechado no infinito a expressão transforma-se em uma integral da linha fechada, que corresponde à própria circulação, ou seja

$$
\Gamma=\oint v \cdot d s
$$

$\mathrm{Na}$ prática, o caminho de integração pode ser fechado se consideramos uma distância bem grande quando comparada com as dimensões da asa. Nesse caso as contribuições podem ser desprezadas pois são pequenas, iguais e de sinais opostos. A variação do fluxo de impulso causada pela asa pode ser escrita como

$$
\dot{I}_{B}-\dot{I}_{A}=\rho \cdot y \cdot v_{0} \cdot \Gamma .
$$

Assim concluímos que a força aplicada na asa neste caso pode ser dada por

$$
F=\rho \cdot y \cdot v_{0} \cdot \Gamma
$$

que é a mesma fórmula de Kutta-Joukowski. Podemos entendê-la como se segue: A sustentação de uma asa equivale à variação do fluxo do impulso vertical causada pela asa. É possível descrever esta relação mediante o conceito de circulação. Mas fica claro que a circulação nunca pode ser a causa da sustentação.

\section{Confecção de um manômetro sensível}

Todos os experimentos descritos podem ser feitos usando um jato de ar gerado por um secador de cabelos. A medição de pressões requer um manômetro bem sensível, porque as diferenças das pressões são pequenas comparadas com a pressão atmosférica. Todas as medidas de pressão são feitas a partir da pressão atmosférica. O esquema na Fig. 23 mostra o arranjo utilizado.

O manômetro consiste de um tubo fino de vidro de comprimento de 60 a 100 centímetros com uma das extremidades curva como mostra a Fig.23. Esta extremidade curva está imersa num pequeno reservatório (béquer, copo, etc.) com água colorida, para facilitar a visualização, e um suporte ajustável, para regular a sensibilidade e para calibrar o manômetro.

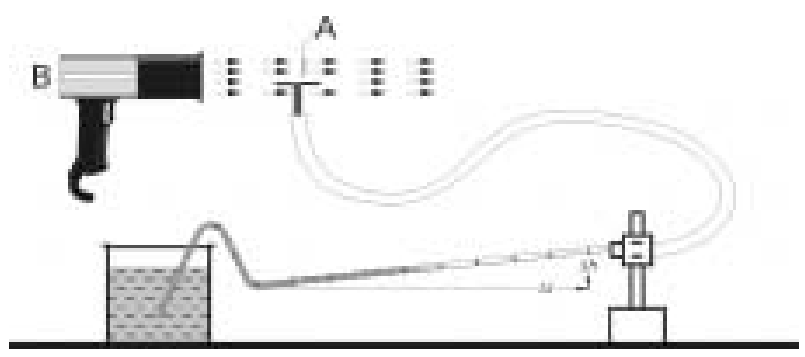

Figura 23. Manômetro sensível de tubo oblíquo. Medição da pressão estática dentro do jato de ar de um secador de cabelos. (A) Ponta de prova com disco perfurado. (B) Secador de cabelos.

$\mathrm{Na}$ outra extremidade do tubo de vidro adaptase uma mangueira de borracha bastante flexível com o mesmo calibre do tubo. A outra extremidade da mangueira possui uma ponta de prova feita de tubo de vidro fino, como o anteriormente descrito. $\grave{A}$ extremidade da ponta de prova deve ter colado sobre si um pequeno disco com perfuração central. Este disco tem por objetivo manter paralelas as linhas de escoamento do fluxo de ar nas vizinhanças da ponta. Quando a extremidade curva for inserida no reservatório e o líquido for sugado, deve-se ter o cuidado para não deixar bolhas de ar no tubo nem gotas do liquido na mangueira flexível, pois ambos prejudicam o bom funcionamento do manômetro. O nível da água é o mesmo no reservatório e no tubo. Se a ponta de prova for colocada numa região de pressão diferente da atmosférica o menisco da água no tubo reage. A diferença entre os níveis do menisco da água dentro do tubo e o menisco da água no reservatório corresponde à diferença das pressões nas duas superfícies líquidas. Para calibrar o manômetro mede-se a inclinação do tubo e marcamse com fita crepe distâncias no tubo com diferenças de alturas correspondentes a diferenças de pressão de 20 a 40 pascal. Lembre-se de que uma variação de um 1 milímetro na altura eqüivale a uma variação de 10 pascal. Então a diferença de pressão referente a uma distância $\Delta s$, entre marcas, é dada por

$$
\Delta p=\rho \cdot g \cdot \Delta s \cdot \tan \alpha,
$$

sendo $\tan \alpha=\Delta h / \Delta l$ como na Fig.23.

Quando realizarmos medições vale lembrar mais uma vez que a posição adequada do disco para medir a pressão estática é a paralela em relação ao escoamento. Se o disco for posicionado perpendicularmente ao escoamento mede-se a pressão total que é a soma da pressão estática e da pressão dinâmica.

Nota: Se não for possível usar um tubo de vidro, pode-se usar uma mangueira de plástico transparente, de pequeno diâmetro, presa numa haste de madeira com fita crepe em distâncias iguais para serem usadas como marcas calibradoras. Um fio de cobre deve ser inserido na extremidade para ser curvado de modo a manter a curvatura como indica a Fig.23. 


\section{Confecção de modelos para demonstra- ções}

Para gerar um fluxo de ar forte existem túneis de vento. Normalmente estes equipamentos não são disponíveis nos laboratórios didáticos. Neste caso, o jato de ar gerado por um secador de cabelos é suficiente para demonstrar todos os efeitos fundamentais. O fluxo de ar produzido pelo secador é estreito por causa do diâmetro de sua saída. Por isso, temos que adaptar os experimentos a esta condição, usando modelos, que caibam dentro do jato.

$\mathrm{Na}$ seção III.5.1 descrevemos experimentos fundamentais para a geração de pressões mediante o desvio do escoamento. O jato de ar passa por uma superfície curva, como apresentado na Fig.9. Esta superfície e todos os modelos foram construídos de tiras de papelão, cartolina, ou cartões postais. Duas tiras foram coladas e modeladas como desejado e foram pressionadas uma contra a outra até a cola secar. Sendo o jato de ar estreito é recomendável colar o modelo confeccionado entre duas placas de vidro ou de acrílico. A distância das placas deve ser mais ou menos igual ao diâmetro da saída do secador, isto é, entre 4 e 5 centímetros. As placas confinam o fluxo. Assim não existem mais interferências laterais no escoamento. A Fig. 24 mostra alguns exemplos feitos desta forma. Além disso os modelos podem ser feitos usando outros tipos de materiais, por exemplo isopor.
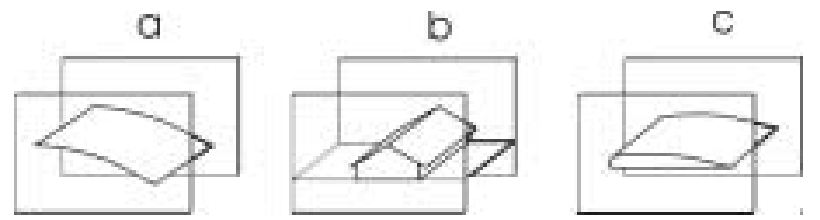

Figura 24. Modelos para serem utilizados em medições de pressão dentro de um fluxo de ar produzido por um secador de cabelos. (a) Superfície curva como a utilizada no arranjo da Fig. 8; (b) casa; (c) aerofólio.

\section{References}

[1] Smith, N.F.:, "Bernoulli and Newton and Fluid Mechanics" The Physics Teacher, 10, 451-455, 1972.
[2] Fletcher, N.H.: "Mechanics of Flight". Physics Education, 385-389, 1975.

[3] Weltner, K.: "A Comparison of Explanations of the Aerodynamic Lifting Force". American Journal of Physics Vol 55, No.1, 50-54, 1987. Weltner, K and Ingelman-Sundberg, M.: "Flugphysik im Unterricht": Physik in der Schule, vol. 35, 3-9, 1997. Weltner, Klaus: "Das Bernoullische Gesetz und seine Fehlinterpretationen" Physik in der Schule, Vol. 36, 43-48, 1998.

[4] Halliday, Resnick, Walker: Fundamentos de Fisica, Vol. 2, Editora LTC, Rio de Janeiro, 1993.

[5] Bergmann-Schaefer: Lehrbuch der Experimentalphysik, Vol. 1, Berlin, 1990.

[6] Anderson, D.; Eberhardt, S.: How Airplanes fly: a physical Description of Lift Sport Aviation, Fevereiro 1999.

[7] Craig, G.M.: Stop Abusing Bernoulli. How Airplanes Really Fly, Editora: Regenerative Press, Anderson, Idiana, 1997.

[8] Waltham, C.: "Flight without Bernoulli" The Physics Teacher, Vol. 36, 457-462, 1998.

[9] Nussenzveig, H. Moisés: Curso de Física Básica, Vol. 2 Editora: Edgard Blücher, São Paulo, 55, 1992.

[10] Gehrtsen; Vogel: Physik, ein Lehrbuch, Editora: De Gruyter, Berlin 1999.

[11] Dubs, F.: Aerodynamik der reinen Unterschallströmung, Editora Birkhäuser, Basel, 1990.

[12] Prandtl, L.: Führer durch die Strömungslehre, Editora: Vieweg, Braunschweig, 1932.

[13] von Kárman: Aerodynamics. Editora McGraw-Hill, New York, 1954.

[14] Schlichting, H., Tuckenbrodt, E.:, Aerodynamik des Flugzeuges, Editora: Teubner, Berlin, 1967.

[15] Kuethe, A.M. e Schetzer, J.D.: Foundations of Aerodynamics. Editora: John Wiley \& Sons, New York, London, 1950.

[16] Lilienthal, O.:, Der Vogelflug als Grundlage der Fliegekunst. Ein Beitrag zur Systematik der Flugtechnik Berlin,1889.

[17] Niermann, K.: Darstellung der Aerodynamik in Schulphysikbüchern, Editora: Leuchtturm, AlsbachBergstrasse, 1989.

[18] Prandtl, L.:, "Applications of modern Hydrodynamics to Aeronautics", NACA Report, No, 116, 161-182, 1921. 